\title{
Histological Study of Induced Incisions on Rabbits' Tongues with Three Diode Lasers with Different Wavelengths in Continuous Mode
}

\author{
Salwa Yammine, ${ }^{1}$ Edgard Jabbour, ${ }^{1}$ Sami El Toum $\mathbb{D}^{2},{ }^{2}$ and Antoine Cassia $\mathbb{D}^{2}$ \\ ${ }^{1}$ Department of Restorative Dentistry and Endodontic, Faculty of Dentistry, Lebanese University, Beirut, Lebanon \\ ${ }^{2}$ Department of Oral Medicine and Maxillofacial Radiology, Faculty of Dentistry, Lebanese University, Beirut, Lebanon \\ Correspondence should be addressed to Sami El Toum; seltoum@idm.net.lb
}

Received 13 December 2017; Accepted 19 March 2018; Published 2 May 2018

Academic Editor: Gary Lopaschuk

Copyright (C) 2018 Salwa Yammine et al. This is an open access article distributed under the Creative Commons Attribution License, which permits unrestricted use, distribution, and reproduction in any medium, provided the original work is properly cited.

\begin{abstract}
Objective. Diode lasers have multiple indications in everyday dental practice. They allow carrying out incisions, coagulation of soft tissue, and Low-Level Laser Therapy. The goal of this study is to compare histologically the tissue interaction zones and edges of an induced laser incision on rabbits' tongues with three different wavelengths of 810,940 , and $980 \mathrm{~nm}$ in continuous mode. Methods. Fourteen male rabbits were divided into six groups. Each animal underwent three incisions of $10 \mathrm{~mm}$ length on the right ventral face of the tongue, carried out in continuous mode with three diode lasers with different wavelengths of 810,940 , and $980 \mathrm{~nm}$. Rabbits were sacrificed at $0,1,2,6$, and 15 hours and 14 days. Five rabbits were sacrificed at 0 hours and 2 hours and one rabbit was sacrificed at 1, 6, and 15 hours and at 14 days. The appearance of neutrophils marked the onset time of the inflammatory reaction. Histological study of the incisions was chosen to evaluate the edges and to measure the depth and width of carbonization and necrotic and inflammatory zones. Healing was evaluated at 14 days. Friedman test was used to assess statistical differences between groups. Results. In the experimental adopted conditions, the carbonization zone was marked by degradation of vacuoles and an elongation of nuclei and was observed on the edges of incisions. Carbonization and necrotic and inflammatory zones were measured for rabbits sacrificed at $0,1,2,6$, and 15 hours but the onset of inflammation zone marked by the infiltration of neutrophils did not appear before 6 hours. The neutrophils infiltration was higher at 15 hours than at 6 hours. Complete healing was shown at 14 days. According to the time for the regularity of the edges, the interpretation was qualitative without a statistical test. The statistical analysis of the three different diode lasers in this study showed nonsignificant difference between the different groups for the depth $(p=0.121)$ and width $(p=0.376)$ of the incisions, the carbonization zone $(p=0.692)$, and the necrotic zone $(p=0.223)$. For the inflammation zone at 6 and 15 hours, statistical analysis was not carried out; only one rabbit was enough to evaluate onset of neutrophils infiltration and to compare its density for 6 and 15 hours. Conclusion. These results indicate that diode laser used in the continuous mode is predictable for induced incision. The use of three diode lasers with different wavelengths of 810,940 , and $980 \mathrm{~nm}$ did not reveal a significant statistical difference according to depth and width of the incision and for carbonization and necrotic zone. The appearance of neutrophils was marked between 4 and 6 hours and was higher at 15 hours.
\end{abstract}

\section{Introduction}

Today, the laser has many indications in routine dental practice. In oral medicine, diode laser can be used for biopsy, coagulation, and Low-level Laser Therapy. The purpose of biopsy is to get a specimen with a sharper and less carbonized edge that permits pathological illustration of the limit. Historically, the first laser was developed in 1960 by Maiman [1]. After that, lasers have been used in medicine and surgery.
Lasers are classified according to the active substance that is stimulated. In the diode laser, the active medium is a semiconductor. This innovative technology has enabled the realization of a compact and low-cost laser [2-4]. There are several wavelengths for the laser diode, but the most used in dentistry are Gallium-Aluminium-Arsenide (GaAlAs) $(810 \mathrm{~nm})$, Gallium-Arsenide (GaAs) $(940 \mathrm{~nm})$, and IndiumGallium-Arsenide (InGaAs) $(980 \mathrm{~nm})$. These wavelengths are well absorbed by hemoglobin and melanin and less absorbed 
by water [5]. With these lasers, penetration depth of biological tissue is between 0.5 and $3 \mathrm{~mm}$ [6-8].

Diode lasers can be used, as clinically indicated, in continuous or pulsed mode and in contact and noncontact mode [9, 10]. The target tissue absorbs laser energy and converses it to thermal effect with temperature increases. Depending on the laser parameters and optical properties of the tissue, the tissue temperature rises differently with multiple zone effects. The tissular reaction zones involved vaporization, carbonization, and necrotic and reversible inflammatory zones. Incisions are accomplished, wherein the temperature is more than $100^{\circ} \mathrm{C}$ and vaporization of intra- and extracellular water is produced, and tissue ablation is achieved [11-13].

Water absorption is the critical factor influencing the energy conversion of surgical lasers that operate in the infrared range. Most tissues are composed of $60-80 \%$ water, so the degree of water absorption determines the ability of the laser to penetrate biological tissue. It is necessary to identify the degree of water absorption for each wavelength [6].

A universal laser does not exist; clinical applications will depend on the chosen wavelength. Lasers currently available in dentistry have different radiation-material interaction [14]. The objective of this study is to compare the edges of an induced incision, on the lingual ventral mucosa of the rabbit, with three wavelength diode lasers of 810,940 , and $980 \mathrm{~nm}$ used in dentistry in continuous mode. Histological analysis permits the evaluation of the depth and width of the induced incision and the carbonization and necrotic and inflammation zones of reactional tissue.

\section{Materials and Methods}

Fourteen male rabbits of local strain Oryctolagus cuniculus domesticus, aged between three and four months and weighing between 1.5 and $2.5 \mathrm{~kg}$, were used. These animals came from conventional breeding at Laboratory of Physiology, Faculty of Medical Sciences (Lebanese University). They were housed in pairs in wire cages $(50 / 75 / 100 \mathrm{~cm})$ with removable bottom, equipped with a feeder and a waterer lollipop. The animals were kept at a temperature of $21 \pm 2^{\circ} \mathrm{C}$ and relative humidity of $60 \pm 5 \%$ with a $12 \mathrm{~h} / 12 \mathrm{~h}$ light/dark cycle. They received a standard diet and water ad libitum. These animals were treated according to the standard norms imposed by the European Union (86/609/EEC).

The fourteen rabbits were divided into six groups. They received an anesthetic dose of $60 \mathrm{mg} / \mathrm{kg}$ of $\mathrm{Nembutal}^{\circledR}$ (sodium pentobarbital, Abbott Laboratories, Inc., Chicago, USA) by intraperitoneal administration. After sedation, the tongue was pulled out with a suture black silk 4/0 (Ethicon, US) according to the point of the tongue. Three diode lasers of different wavelengths were used; the first one is LaserSmile ${ }^{\circledR}$ with wavelength of $810 \mathrm{~nm}$ (group $\mathrm{C1}$ ), the second one is ezlase $^{\circledR}$ with wavelength of $940 \mathrm{~nm}$ (group C2), and the third one is HOYA ConBio ${ }^{\circledR}$ with wavelength of $980 \mathrm{~nm}$ (group C3). Each rabbit underwent three incisions on the ventral surface of the tongue, respectively, with the three lasers used by random position. The power used is two watts in continuous mode delivered with an optical fiber of $400 \mu \mathrm{m}$. The tip of the fiber was "initiated" by using a blue articulating paper

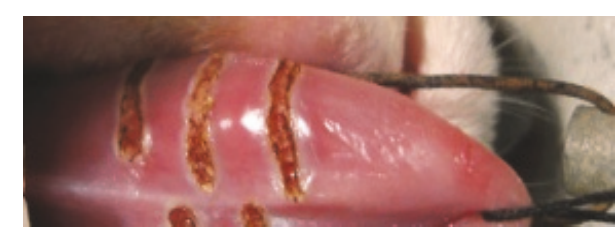

FIGURE 1: Induced incisions with three different wavelength diode lasers of 810,940 , and $980 \mathrm{~nm}$ on the ventral side of the tongue of the rabbit; from top of the tongue, 980, 940, and $810 \mathrm{~nm}$ laser-induced incisions.

with $1.5 \mathrm{~W}$ pulsed $30 \mathrm{~ms} / 30 \mathrm{~ms}$. The fiber was also marked up to $2 \mathrm{~mm}$ in length to permit a gauge when performing incision. Each incision had $10 \mathrm{~mm}$ length and $2 \mathrm{~mm}$ depth and was performed using the activated portion of the fiber as a marker. The position of each relative to the incision or the tip of the tongue has been recorded to recognize the incision in histological sections (Figure 1). A lethal dose of $100 \mathrm{mg} / \mathrm{kg}$ was administered at $0 \mathrm{~h}, 1 \mathrm{~h}, 2 \mathrm{~h}, 6 \mathrm{~h}, 15 \mathrm{~h}$, and 14 days after application of the laser on the tongue and the tongue was immediately dissected and introduced in a solution of $10 \%$ formol. The first five rabbits were sacrificed at 0 hours, one rabbit was sacrificed at 1 hour, five rabbits were sacrificed at 2 hours, and one rabbit was sacrificed at 6 and 15 hours and 14 days, respectively.

Specimens were included in paraffin blocks, and sections of 3 microns in series were realized and stained with hematoxylin-eosin. The histomorphometric measurements were done under a light microscope (Olympus Bx 4500) connected to a digital camera (Nikon Coolpix 4500) at a magnification of $\mathrm{x} 4, \mathrm{x} 10$, and $\mathrm{x} 40$ (Figure 2). Three sections per tongue for a total of twelve samples were analyzed manually with software UTHSCSA ImageTool 3.00. The length and width of the incisions and the diameter of each region were measured in each section after inclusion of specimens in paraffin. The specimens were examined separately by two double-blinded histopathologists, and the agreement was reached by estimating the histological changes due to thermal damage by laser.

\section{Statistical Analysis}

The Statistical Package for the Social Sciences (SPSS for Windows, version 20.0, Chicago, IL, USA) was adopted to perform the statistical analysis of data. The variables to be measured were the depth and width of the incisions, the carbonization area, and the necrotic area. Means and standard deviations were reported for each variable.

The edges of the incisions, the inflammatory reaction, and healing were controlled qualitatively by histological examination without statistical analysis.

Friedman test was used for statistical comparison between the three groups of laser transmission: $\mathrm{Cl}$ (continuous mode wavelength of $810 \mathrm{~nm}$ ), C2 (continuous mode wavelength of $940 \mathrm{~nm}$ ), and C3 (continuous mode wavelength of $980 \mathrm{~nm}$ ). A $p$ value less than 0.05 was deemed statistically significant. Rabbits sacrificed at 0,1 , and 2 hours were pooled for the statistical evaluation of the depth and width of the 


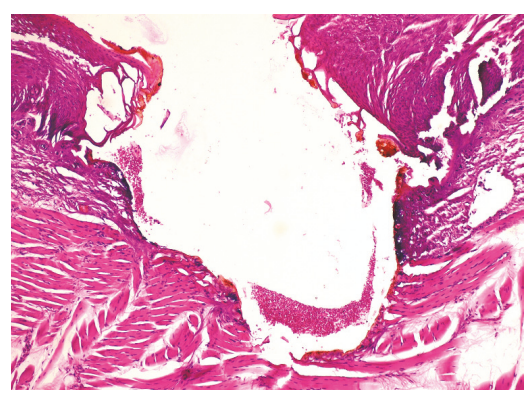

(a) Diode laser $(810 \mathrm{~nm}) \mathrm{cw} \times 10$

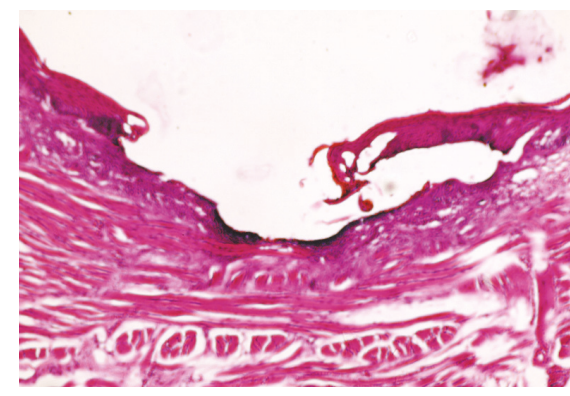

(b) Diode laser $(940 \mathrm{~nm}) \mathrm{cw} \times 10$

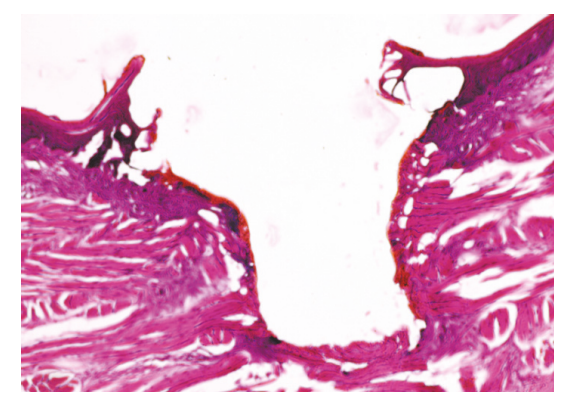

(c) Diode laser $(980 \mathrm{~nm}) \mathrm{cw} \times 10$

Figure 2: Histological sections (a), (b), and (c) of incisions made with diode lasers $(810 \mathrm{~nm}, 940 \mathrm{~nm}$, and $980 \mathrm{~nm}) \mathrm{cw}$ : carbonization, the presence of dense eosinophilic layers (denatured collagen) and vascular changes (x10, H\&E staining).

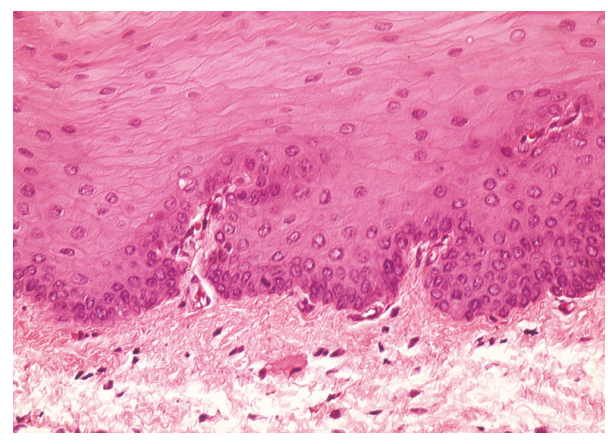

FIGURE 3: Histological view showed the presence of congestion (neutrophils and monocytes), edema (spaced fibers and cells), and leukocyte diapedesis of PMN after $6 \mathrm{~h}$ (x40, H\&E staining).

incisions, carbonization, and necrotic zones. Graphs (error bars representing each variable's mean and its $95 \%$ confidence interval) were drawn to show differences between groups.

\section{Results}

The sections from the ventral face of the rabbit's tongue using the diode laser $(810,940$, and $980 \mathrm{~nm})$ showed a similar thermal denaturation, such as carbonization, characterized histologically by degradation vacuoles, pyknosis, karyolysis, karyorrhexis, and elongation of nuclei at the edges of the incisions (Figure 2).

The incisions made in continuous mode showed more significant inflammatation at 15 hours than at 6 hours, which was marked by a high concentration of neutrophils, and healing was completed at 14 days. Groups $\mathrm{C} 1, \mathrm{C} 2$, and C3, sacrificed, respectively, at 0 hours, 1 hour, and 2 hours, noted the absence of polymorphonuclear (PMN) unlike those sacrificed at 6 and 15 hours (Figure 3).

The carbonized region (necrosis) is characterized by the absence of the cores, whereas the coagulated region is characterized by elongated cells with pycnotic nuclei and homogenized cytoplasm. A swelling layer with PMN infiltration was noted in the underlying conjunctiva (Figure 2).

Rabbits well tolerated the incision with the laser without intraoperative or postoperative adverse effects. The induced

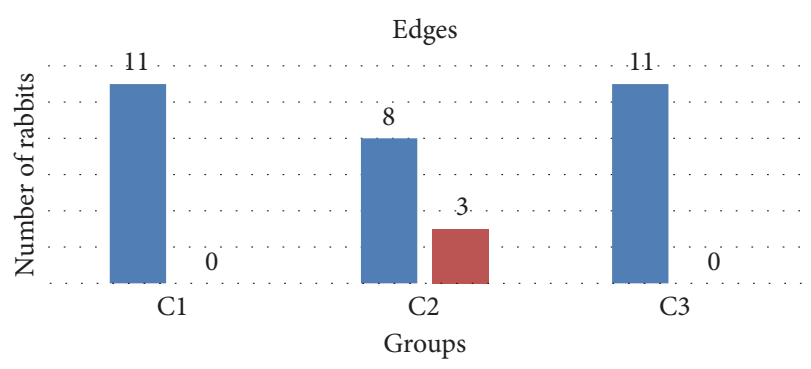

- Irregular

- Regular

FIGURE 4: The regular edges were sharper and more defined and straight in $\mathrm{C} 1$ and $\mathrm{C} 3$ groups in continuous mode unlike the jagged edges in continuous mode in $\mathrm{C} 2$ group.

incisions had complete healing after 14 days without functional loss. Table 1 illustrates the result of the measures of different parameters.

The edges of the incisions were microscopically evaluated and classified into two groups: an incision with regular edges where well-marked margins edges were noted, and irregular edges were poorly defined edges, interspersed on margins. The interpretation of the values was qualitative for this parameter. With diode laser with wavelength of $940 \mathrm{~nm}$, three of the 11 rabbits controlled showed an irregular edge (Figure 4).

The depth of the incisions induced by diode laser with wavelengths of $810 \mathrm{~nm}, 940 \mathrm{~nm}$, and $980 \mathrm{~nm}$ showed that the average of the depth was smaller with group C2 $(940 \mathrm{~nm})$ (Figure 5). Statistically, there was no significant difference between the three groups, C1, C2, and C3 ( $p=0.121)$ (Table 2).

The width of incisions was smaller in group C3 $(980 \mathrm{~nm})$ in comparison with groups $\mathrm{C} 1$ and $\mathrm{C} 2$ (Figure 6), but the difference was not statistically significant $(p=0.376)$ (Table 2).

The carbonization zone in this study was more marked with diode laser with wavelength of $940 \mathrm{~nm}$ (Figure 7) but did not reveal any statistically significant difference between the three groups $(p=0.692)$ (Table 2$)$. 
TABLE 1: Results of the fourteen rabbits concerning the depth and width of the incision, the carbonization, and necrotic and inflammatory zones.

\begin{tabular}{|c|c|c|c|c|c|c|c|c|}
\hline Rabbits & Sacrifice time & Groups & Depth & Width & Carbonization zone & Necrosis zone & Inflammatory zone & Edges \\
\hline \multirow{3}{*}{1} & \multirow{3}{*}{0 hours } & $\mathrm{C} 1$ & & & & & & Regular \\
\hline & & $\mathrm{C} 2$ & 1.20 & 2.00 & 0.10 & 1.00 & & Regular \\
\hline & & $\mathrm{C} 3$ & 3.80 & 3.00 & 0.10 & 1.50 & & Regular \\
\hline \multirow{3}{*}{2} & \multirow{3}{*}{0 hours } & $\mathrm{Cl}$ & 6.50 & 0.60 & 0.05 & 0.30 & & Regular \\
\hline & & $\mathrm{C} 2$ & 3.50 & 2.00 & 0.10 & 0.50 & & Irregular \\
\hline & & $\mathrm{C} 3$ & 8.00 & 7.00 & 0.20 & 1.00 & & Regular \\
\hline \multirow{3}{*}{3} & \multirow{3}{*}{0 hours } & $\mathrm{Cl}$ & 14.00 & 3.50 & 0.10 & 0.50 & & Regular \\
\hline & & $\mathrm{C} 2$ & 2.50 & 3.50 & 0.10 & 0.50 & & Regular \\
\hline & & $\mathrm{C} 3$ & 14.00 & 2.50 & 0.10 & 0.50 & & Regular \\
\hline \multirow{3}{*}{4} & \multirow{3}{*}{0 hours } & $\mathrm{C} 1$ & 3.00 & 3.00 & 0.10 & 0.70 & & Regular \\
\hline & & $\mathrm{C} 2$ & 2.50 & 5.50 & 0.10 & 1.00 & & Regular \\
\hline & & $\mathrm{C} 3$ & 5.00 & 3.00 & 0.10 & 0.80 & & Regular \\
\hline \multirow{3}{*}{5} & \multirow{3}{*}{0 hours } & $\mathrm{Cl}$ & 5.00 & 3.00 & 0.10 & 0.40 & & Regular \\
\hline & & $\mathrm{C} 2$ & 6.00 & 2.50 & 0.10 & 0.50 & & Irregular \\
\hline & & $\mathrm{C} 3$ & 9.50 & 2.00 & 0.10 & 0.50 & & Regular \\
\hline \multirow{3}{*}{6} & \multirow{3}{*}{1 hour } & $\mathrm{Cl}$ & 1.40 & 2.00 & 0.10 & 0.50 & & Regular \\
\hline & & $\mathrm{C} 2$ & 1.20 & 1.50 & 0.10 & 0.30 & & Regular \\
\hline & & $\mathrm{C} 3$ & 0.00 & 0.00 & 0.00 & 0.00 & & \\
\hline \multirow{3}{*}{7} & \multirow{3}{*}{2 hours } & $\mathrm{C} 1$ & 2.50 & 2.00 & 0.10 & 0.70 & & Regular \\
\hline & & $\mathrm{C} 2$ & 0.00 & 0.00 & 0.00 & 0.00 & & Regular \\
\hline & & $\mathrm{C} 3$ & 3.00 & 1.50 & 0.10 & 1.00 & & Regular \\
\hline \multirow{3}{*}{8} & \multirow{3}{*}{2 hours } & $\mathrm{Cl}$ & 2.00 & 2.50 & 0.10 & 0.30 & & Regular \\
\hline & & $\mathrm{C} 2$ & 6.00 & 3.00 & 0.20 & 1.00 & & Irregular \\
\hline & & $\mathrm{C} 3$ & 2.50 & 3.00 & 0.10 & 0.40 & & Regular \\
\hline \multirow{3}{*}{9} & \multirow{3}{*}{2 hours } & $\mathrm{C} 1$ & 9.00 & 6.00 & 0.20 & 0.50 & & Regular \\
\hline & & $\mathrm{C} 2$ & 4.80 & 3.00 & 0.50 & 0.50 & & Regular \\
\hline & & $\mathrm{C} 3$ & 2.50 & 3.50 & 0.20 & 0.50 & & Regular \\
\hline \multirow{3}{*}{10} & \multirow{3}{*}{2 hours } & $\mathrm{C} 1$ & 4.00 & 4.00 & 0.10 & 0.50 & & Regular \\
\hline & & $\mathrm{C} 2$ & 1.20 & 3.00 & 0.10 & 0.50 & & Regular \\
\hline & & $\mathrm{C} 3$ & 3.80 & 2.00 & 0.20 & 0.50 & & Regular \\
\hline \multirow{3}{*}{11} & \multirow{3}{*}{2 hours } & $\mathrm{Cl}$ & 3.00 & 4.00 & 0.10 & 1.00 & & Regular \\
\hline & & $\mathrm{C} 2$ & 1.00 & 5.00 & 0.10 & 1.00 & & Regular \\
\hline & & $\mathrm{C} 3$ & 4.00 & 2.50 & 0.10 & 1.00 & & Regular \\
\hline \multirow{3}{*}{12} & & $\mathrm{C} 1$ & 4.50 & 3.00 & 0.10 & 0.30 & 0.00 & \\
\hline & 6 hours & $\mathrm{C} 2$ & 1.50 & 1.80 & 0.10 & 0.30 & 1.00 & \\
\hline & & $\mathrm{C} 3$ & 1.50 & 1.80 & 0.10 & 0.30 & 0.50 & \\
\hline & & $\mathrm{Cl}$ & 1.50 & 2.00 & 0.00 & 2.00 & 8.00 & \\
\hline 13 & 15 hours & $\mathrm{C} 2$ & 2.30 & 4.50 & 0.00 & 2.00 & 2.00 & \\
\hline & & $\mathrm{C} 3$ & 2.50 & 6.00 & 0.00 & 3.00 & 7.00 & \\
\hline & & $\mathrm{Cl}$ & 0.00 & 0.00 & 0.00 & 0.00 & 0.00 & \\
\hline 14 & 14 days & $\mathrm{C} 2$ & 0.00 & 0.00 & 0.00 & 0.00 & 0.00 & \\
\hline & & $\mathrm{C} 3$ & 0.00 & 0.00 & 0.00 & 0.00 & 0.00 & \\
\hline
\end{tabular}

The necrosis (necrotic zone) was highest with diode laser with wavelength of $980 \mathrm{~nm}$ (group C3) (Figure 8), but there was no significant difference between $\mathrm{C} 1, \mathrm{C} 2$, and C3 ( $p=$ 0.223) (Table 2).
The comparison of the inflammatory zones between $\mathrm{Cl}$, $\mathrm{C} 2$, and $\mathrm{C} 3$ in this study was qualitative and appeared after 6 hours and was more marked at 15 hours than that at 6 hours with a high density of neutrophils. The inflammatory reaction 
TABLE 2: Comparison of the three groups for the depth, width, carbonization, and necrotic zone.

\begin{tabular}{lcccc}
\hline & C1 & C2 & C3 & $p$ value \\
\hline Depth & $4.70+/-3.67$ & $2.71+/-1.98$ & $4.69+/-3.95$ & 0.121 \\
Width & $2.97+/-1.36$ & $2.94+/-1.56$ & $2.90+/-1.91$ & 0.376 \\
Carbonization & $0.10+/-0.05$ & $0.13+/-0.13$ & $0.11+/-0.07$ & 0.692 \\
Necrotic zone & $0.64+/-0.47$ & $0.68+/-0.52$ & $0.79+/-0.76$ & 0.223 \\
Inflammation & $4.00+/-4.00$ & $1.50+/-1.00$ & $3.75+/-3.25$ \\
\hline
\end{tabular}

*Friedman test.

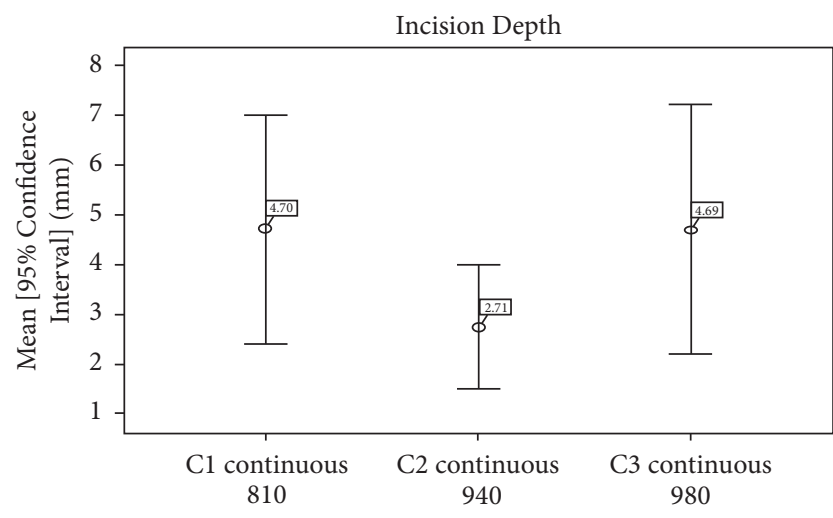

Figure 5: Average incision depths of groups C1, C2, and C3.

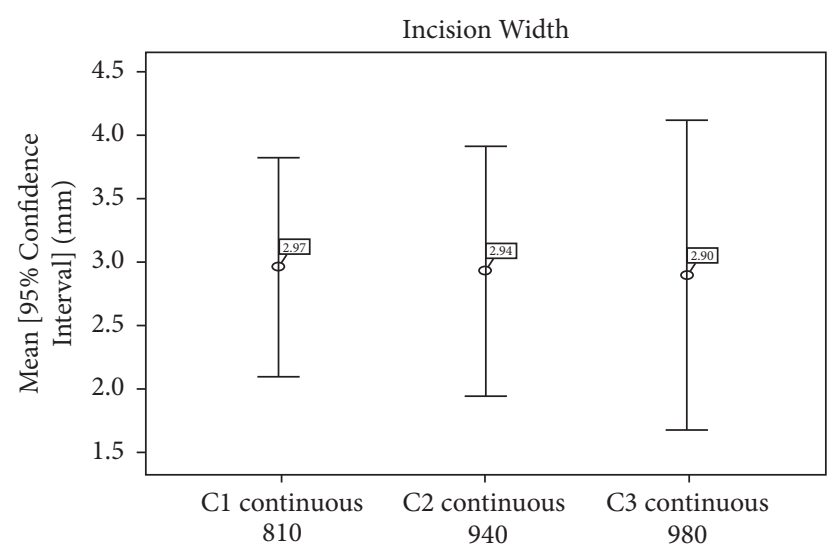

FIGURE 6: Average incision widths of groups C1, C2, and C3.

was the lowest with C2 and equal with $\mathrm{C} 1$ and C3 (Figure 9). No statistical analysis of the inflammatory response was done due to the limited number of rabbits in each group (Table 2).

\section{Discussion}

Diode lasers have been used in dentistry since 1995. Today, several wavelengths of diode laser are used in dentistry: 655, $810,940,980$, and $1.064 \mathrm{~nm}$. The purpose of this study was to compare induced incisions on the ventral lingual mucosa of the rabbit using three diode lasers with wavelengths of 810 , 940 , and $980 \mathrm{~nm}$ in continuous mode.

The water absorption is highest with $980 \mathrm{~nm}$ lasers, followed by $940 \mathrm{~nm}$ and $810 \mathrm{~nm}$. Also, hemoglobin absorption is highest with $980 \mathrm{~nm}$ laser and then $810 \mathrm{~nm}$ and is approximately the same as $940 \mathrm{~nm}$. Melanin absorption is highest with $810 \mathrm{~nm}$ and then $940 \mathrm{~nm}$ and $980 \mathrm{~nm}$ lasers [4, 9-11, 15].

The diode lasers with 810,940 , and $980 \mathrm{~nm}$ wavelengths are ideally suited for soft tissue treatments because they are very well absorbed by hemoglobin and melanin, two great compounds in the oral soft tissues. Diode lasers are used to cut or destruct a tissue and to coagulate bleeding $[4,7,10$, $12,15-17]$. With these wavelengths, the penetration depth in biological tissues was relatively high at approximately $0.5-$ $3 \mathrm{~mm}[6,18]$.

Borchers [19] reported that cutting efficiency of a laser diode with a wavelength of $980 \mathrm{~nm}$ is greater than $810 \mathrm{~nm}$. The $810 \mathrm{~nm}$ laser had a lower absorption by water, $\mathrm{HbO}_{2}$, and hemoglobin then $980 \mathrm{~nm}$ laser. The $980 \mathrm{~nm}$ laser can create more heat energy to the surface and deep penetration. The area of necrosis is larger and deeper. Bach et al. [20] reported in their in vitro study that there was no histological difference between the $810 \mathrm{~nm}$ diode laser and the $980 \mathrm{~nm}$ diode laser when both are used in the same mode. Using the laser diode in continuous mode, the cut was flattened and regular [19] and the cutting efficiency was not low.

In this study, the edges of incisions were well defined and were consistent with the 810 and $980 \mathrm{~nm}$ diode lasers used in a continuous mode but less with the $940 \mathrm{~nm}$ laser. The cutting efficiencies of the three lasers were identical. No statistically significant difference for the depth and the width of the incision was reported.

Other parameters other than wavelength can be involved in the cutting efficiency such as power, frequency, pulse duration, and fiber diameter. Parameters such as fluence and treatment time were related to tissue type (pigmented tissue), race, and blood circulation. The characteristics and parameters of the laser (output power, wavelength, terms transmission, type of optical fiber used, and the affinity with the target tissue) may condition the width and intensity of the thermal damage to tissue $[5,10,19-22]$.

Our study aimed to compare the efficacy and tissue damage of different diode laser wavelengths on the oral tissue. The power, fiber diameter, target tissue, and operator were the same for the three lasers, which only varied by their wavelengths. The target was to realize an incision with 8 to $10 \mathrm{~mm}$ with the same number of passes and the same pressure.

In this study, the average depth was $4.70+/-3.67$ for $810 \mathrm{~nm}$ laser, $4.69+/-3.95 \mathrm{~mm}$ for $980 \mathrm{~nm}$ laser, and 2.71 $+/-1.98 \mathrm{~mm}$ for $940 \mathrm{~nm}$ laser; but the difference was not statistically significant ( $p=0.121$ ), Whereas the width of the incision in this study was $2.97+/-1.36 \mathrm{~mm}$ for $810 \mathrm{~nm}$ laser, 


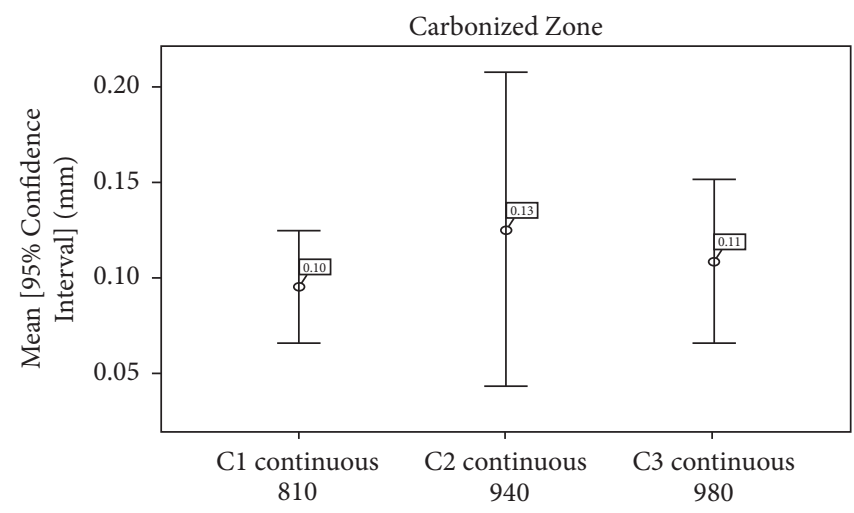

FIGURE 7: Average carbonized zones of groups C1, C2, and C3.

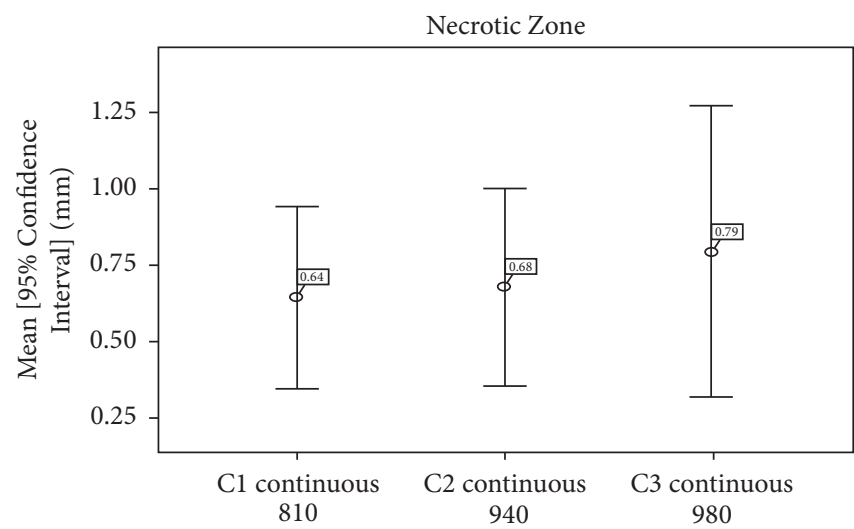

FIGURE 8: Average necrosis zones of groups C1, C2, and C3.

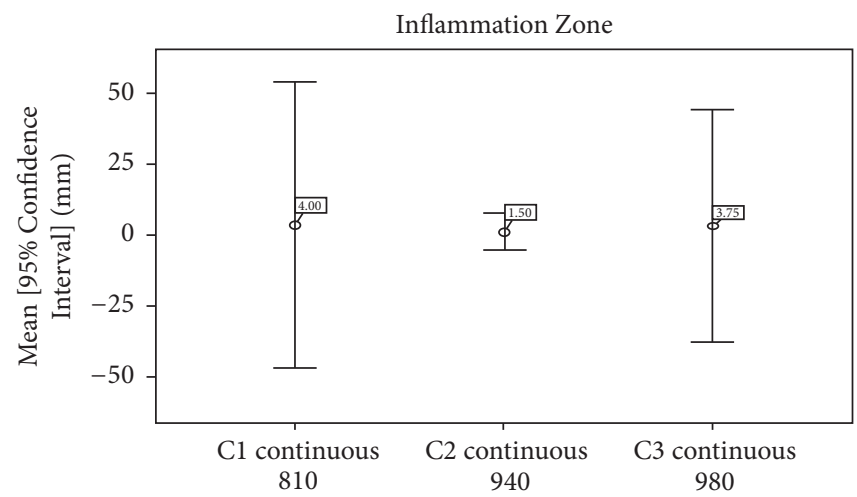

FIGURE 9: Lower inflammatory response in group C2 versus groups $\mathrm{C} 1$ and $\mathrm{C} 3$.

$2.94+/-1.56 \mathrm{~mm}$ for $940 \mathrm{~nm}$ laser, and $2.90+/-1.91 \mathrm{~mm}$ for $980 \mathrm{~nm}$ laser, with no statistical significance as well. Carbonization and necrotic and inflammatory zones were approximately the same for the three lasers, and the difference was not statistically significant.

Goharkhay et al. [15] reported that the horizontal and vertical tissue destruction dimension does not depend on the diameter of the fiber or the transmission mode ( $\mathrm{CW}$ or pulsed) but only depends on the average power used.
Brochers [19] reported that the risk of carbonization of tissue destruction increases when the diameter of the fiber decreases. Carbonization, in turn, changes the absorption of the treated tissue and increases due to the dark color that absorbs the laser energy much better than light or bright colors. This means that there is more thermal energy applied to the surface and necrosis of adjacent structures is created. Thus, the parameters used may influence the degree of carbonization [10, 20, 23-26]. For Schäfer [27], the cause of the 
carbonization is therefore not recounted to the wavelength; rather it may be related to the characteristics of the laser timing. The laser used in continuous mode increases the tissue temperature more than pulsed mode. The burned tissue also exhibits a higher absorption coefficient than healthy tissue $[8,27]$. The evaluation of the ability of healing after 14 days showed complete recovery with a power of 2 watts in continuous mode. However, Bryant et al. [28] found very slow healing with 3 watts of power. The incisions made with continuous mode showed an inflammatory response without delay in the healing process. Jin et al. [29] compared the healing of incisions made with a scalpel or a diode laser and an Er,Cr:YSGG laser on oral mucosa of guinea pigs and reported that there is less tissue damage with the use of a scalpel compared to an Er,Cr:YSGG laser and diode laser.

The diode laser is a valuable therapeutic tool for excisional and incisional biopsy in oral lesions but it induced significant thermal effects. However, from a clinical point of view, the limit of the specimen is essential, and the carbonization and the necrosis zone made the identification of the healthy tissue difficult. To submit a histological diagnosis, specimens must be intact and readable; the marginal integrity is very critical to evaluate the complete excision of malignant and premalignant tissue. There is considerable controversy about the use of diode laser in oral pathology. The specimens obtained with a diode laser have good histological readability $[6,15,30]$. However, characteristics and parameters of the laser (output power, wavelength, emission mode, type of optic fiber used, and affinity for the target tissue) can condition the width and the severity of thermal damage to tissue $[31,32]$.

\section{Conclusion}

Nowadays, no laser dentistry can completely replace conventional instruments while improving clinical outcomes. In oral pathology, where biopsy is the cornerstone of the diagnosis and therapy for many lesions, the laser can find its way through its various features (hemostatic, bactericidal, no pain, sutures, etc.). This study showed that the three diode lasers with different wavelengths $(810 \mathrm{~nm}, 940 \mathrm{~nm}$, and $980 \mathrm{~nm}$ ) in continuous mode could be used for the incision of oral mucosa. In continuous mode, the edges of the incisions have been shown to be regular with the three types of lasers. The carbonization and necrotic and inflammatory zones were not statistically different between the three lasers.

The diode lasers are a favorable surgical option while executing incisions on the intraoral mucosa. The advantages of laser therapy include the minimal postoperative pain, the conservation of the specific site with minimal surgical invasion, and elimination of the need for a suture.

\section{Conflicts of Interest}

The authors declare that they have no conflicts of interest.

\section{References}

[1] T. H. Maiman, "Stimulated optical radiation in Ruby," Nature, vol. 187, no. 4736, pp. 493-494, 1960.
[2] S. Pirnat, "Versatility of an $810 \mathrm{~nm}$ diode laser in dentistry: an overview," Journal of Laser and Health Academy, vol. 4, pp. 1-9, 2007.

[3] F. Goldstep, "Soft tissue diode laser: Where have you been all my life?" Oral Health, pp. 34-38, 2009.

[4] F. Goldstep and G. Freedman, "Diode laser: The soft-tissue handpiece," Laser International Magazine of Laser Dentistry, pp. 16-18, 2012.

[5] G. Romanos and G.-H. Nentwig, "Diode laser $(980 \mathrm{~nm})$ in oral and maxillofacial surgical procedures: Clinical observations based on clinical applications," Journal of Clinical Laser Medicine \& Surgery, vol. 17, no. 5, pp. 193-197, 1999.

[6] A. Aoki, K. Mizutani, A. A. Takasaki et al., "Current status of clinical laser applications in periodontal therapy," General dentistry, vol. 56, no. 7, pp. 674-687, 2008.

[7] W. T. Baxter, S. F. Mironov, A. V. Zaitsev, J. Jalife, and A. M. Pertsov, "Visualizing excitation waves inside cardiac muscle using transillumination," Biophysical Journal, vol. 80, no. 1, pp. 516530, 2001.

[8] J. M. White, S. I. Chaudhry, J. J. Kudler, N. Sekandari, M. L. Schoelch, and S. Silverman, "Nd: YAG and CO2 laser therapy of oral mucosal lesions," Journal of Clinical Laser Medicine \& Surgery, vol. 16, pp. 299-304, 1998.

[9] A. Moritz, N. Gutknecht, O. Doertbudak et al., "Bacterial reduction in periodontal pockets through irradiation with a diode laser: A pilot study," Journal of Clinical Laser Medicine \& Surgery, vol. 15, no. 1, pp. 33-37, 1997.

[10] A. Moritz, U. Schoop, K. Goharkhay et al., "Treatment of periodontal pockets with a diode laser," Lasers in Surgery and Medicine, vol. 22, no. 5, pp. 302-311, 1998.

[11] D. J. Coluzzi, "An overview of laser in dentistry, fundamentals of lasers," Dental Clinics of North America, vol. 54, no. 1, pp. 35-53, 2010.

[12] D. J. Coluzzi, "Absorption of laser by dental tissue," Journal of Dental Lasers, vol. 18, no. 3, pp. 123-131, 2010.

[13] J. G. Manni, Dental Applications of Advanced Lasers, JGM Associates, Burlington, Mass, USA, 2004.

[14] C. Alamarguy, Le Laser et ses Utilisations en Odontologie Conservatrice [Thèse de Diplôme d'Etat], Université Nancy Poincaré, 2011.

[15] K. Goharkhay, A. Moritz, P. Wilder-Smith et al., "Effects on oral soft tissue produced by a diode laser in vitro," Lasers in Surgery and Medicine, vol. 25, no. 5, pp. 401-406, 1999.

[16] C. J. Walinski, "Irritation fibroma removal: A comparison of two laser wavelengths," General dentistry, vol. 52, no. 3, pp. 236-238, 2004.

[17] T. C. Adams and P. K. Pang, "Lasers in aesthetic dentistry," Dental Clinics of North America, vol. 48, no. 4, pp. 833-860, 2004.

[18] A. Moritz, F. Beer, and K. Goharkhay, Oral Laser Application, Quintessence, 2006.

[19] R. Borchers, Comparison of Diode Lasers in soft- tissue surgery using $c w$-and superpulsed mode: an in vivo study [M.S. thesis], RWTH Aachen, 2008.

[20] G. Bach, H. K. Koch, U. Hellerich, and T. Venzke, "Konventionelle Diodenlaser versus Hochpulstechnik," Laser Journal, vol. 1, pp. 18-20, 2008.

[21] H. H. Horch, Laser in der oralen Chirurgie. Vortrag beim11, Internationalen Jahreskongress der DGL, Berlin, Germany, 2002. 
[22] H. J. Hartmann and G. Bach, "Diodenlaser- Oberflächen- Dekontamination in der Periimplantitis therapie," Eine DreiJahres- Studie ZWR, vol. 106, pp. 524-526, 1997.

[23] P. Black, "Der Dentallaser in der oralen Chirurgie-MastertheseTeil2," Laser Journal, vol. 1, pp. 16-21, 2007.

[24] H. M. Saleh and A. M. Saafan, "Excision biopsy of tongue lesions by diode laser," Photomedicine and Laser Surgery, vol. 25, no. 1, pp. 45-49, 2007.

[25] P. Janda, R. Sroka, B. Mundweil, C. S. Betz, R. Baumgartner, and A. Leunig, "Comparison of thermal tissue effects induced by contact application of fiber guided laser systems," Lasers in Surgery and Medicine, vol. 33, no. 2, pp. 93-101, 2003.

[26] A. J. Welch, "The Thermal Response of Laser Irradiated Tissue," IEEE Journal of Quantum Electronics, vol. 20, no. 12, pp. 14711481, 1984.

[27] O. Schäfer, "The evolution of the diode laser," Laser Journal, vol. 14, 2011.

[28] G. L. Bryant, J. M. Davidson, R. H. Ossoff, C. G. Garrett, and L. Reinisch, "Histologic study of oral mucosa wound healing: a comparison of a 6.0 - to $6.8-\mu \mathrm{m}$ pulsed laser and a carbon dioxide laser," The Laryngoscope, vol. 108, no. 1, pp. 13-17, 1998.

[29] J.-Y. Jin, S.-H. Lee, and H.-J. Yoon, "A comparative study of wound healing following incision with a scalpel, diode laser or Er,Cr:YSGG laser in guinea pig oral mucosa: A histological and immunohistochemical analysis," Acta Odontologica Scandinavica, vol. 68, no. 4, pp. 232-238, 2010.

[30] S. Capodiferro, E. Maiorano, A. M. Loiudice, F. Scarpelli, and G. Favia, "Oral laser surgical pathology: a preliminary study on the clinical advantages of diode laser and on the histopathological features of specimens evaluated by conventional and confocal laser scanning microscopy." Minerva stomatologica, vol. 57, no. 1-2, pp. 1-67, 2008.

[31] L. R. Eversole, "Laser artifacts and diagnostic biopsy," Oral Surgery, Oral Medicine, Oral Pathology, Oral Radiology, and Endodontology, vol. 83, no. 6, pp. 639-640, 1997.

[32] J. M. White, H. E. Goodis, and C. L. Rose, "Use of the pulsed Nd:YAG laser for intraoral soft tissue surgery," Lasers in Surgery and Medicine, vol. 11, no. 5, pp. 455-461, 1991. 


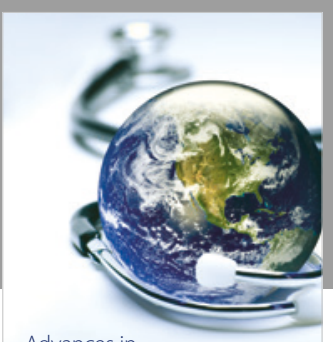

Advances in
Public Health

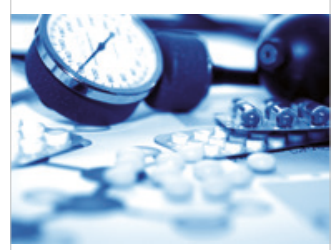

Case Reports in

Medicine

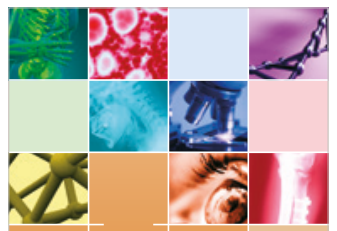

niernational Journal of

Biomaterials
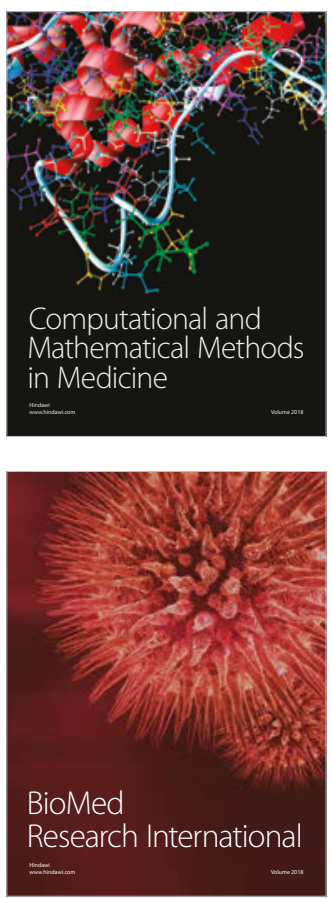

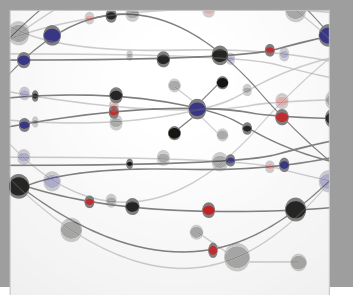

The Scientific World Journal Dentistry

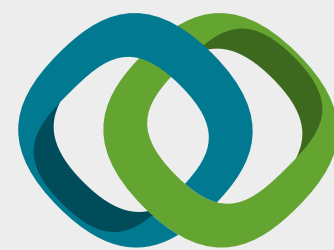

Hindawi

Submit your manuscripts at

www.hindawi.com
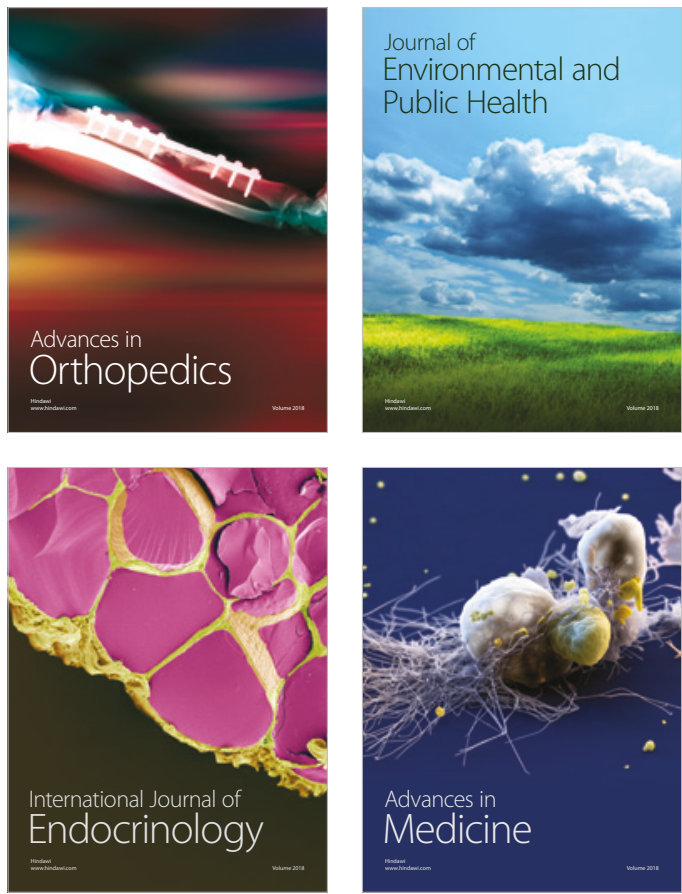
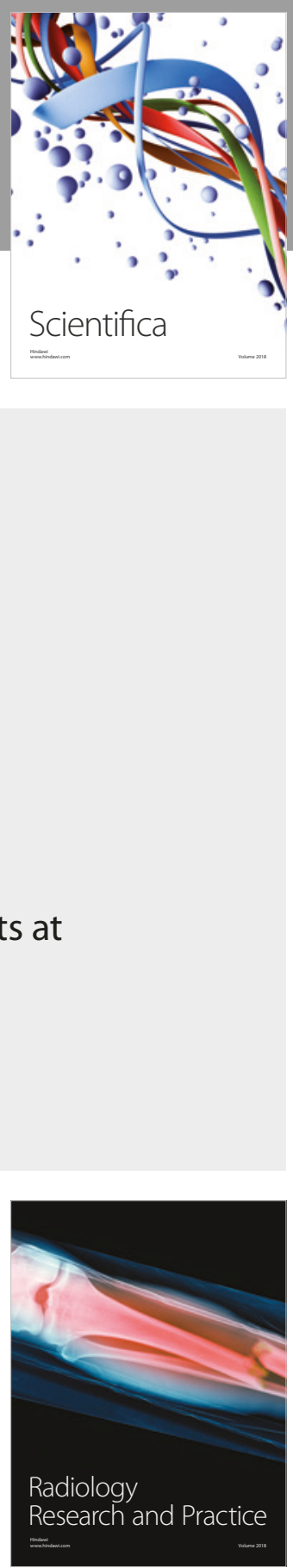

Scientifica

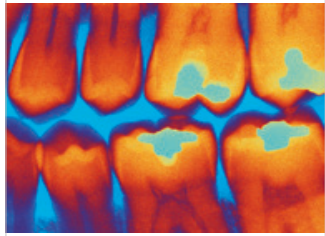

Case Reports in

Dentistry
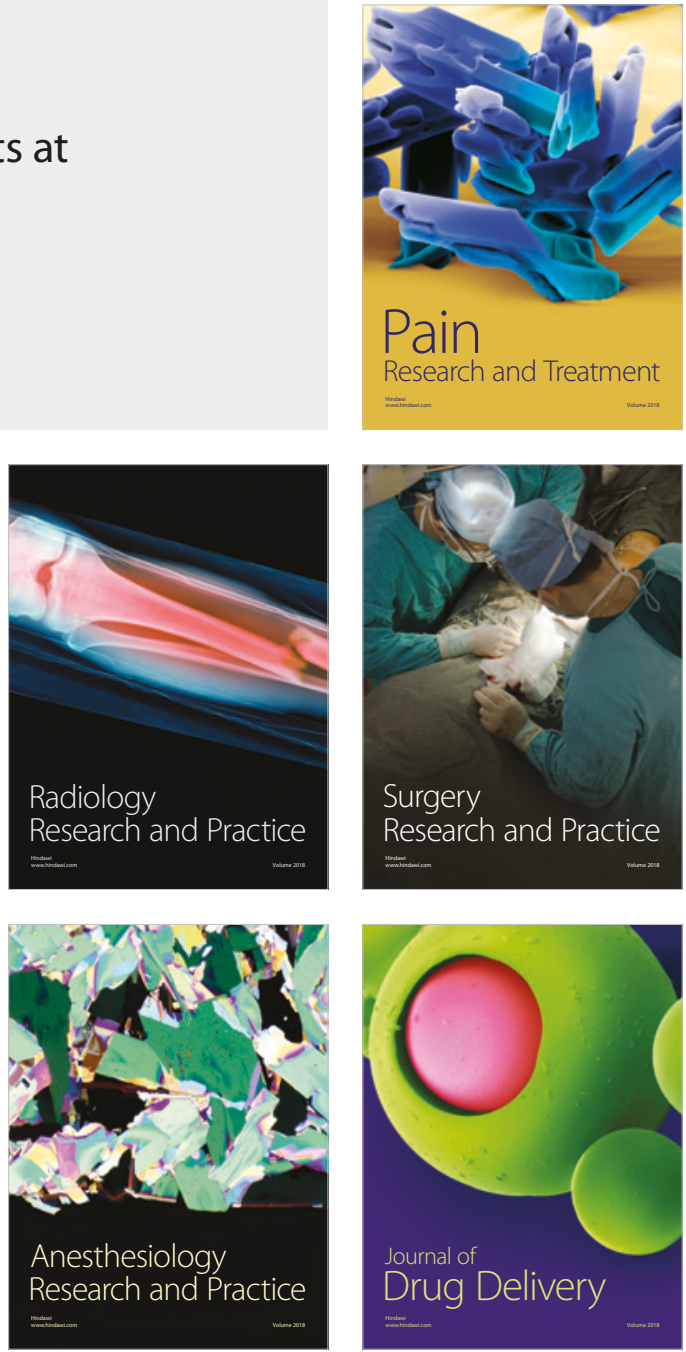